\title{
Intelligence for beginners?
}

\author{
Donald D. Dorfman
}

EYSENCK'S new book on intelligence is his first to appear since Leon Kamin reported gross irregularities in Sir Cyril Burt's data. The main purpose of his book is to present "what to the author appears to be the paradigm towards which the research of the past 80 years converges" (page 6 ). The book is "intended for beginners" (page 6). An author of a work intended for beginners has an obligation to give a balanced and scrupulous description and analysis of the historical and scientific data.

On page one of his book, Eysenck refers the reader - presumably a beginner - to his appendix A which "gives a short account of the facts of the Burt affair". He implies in that appendix that Arthur Jensen was the first to discover anomalies in Burt's data. Leon Kamin - the actual discoverer - is never mentioned in that historical account.

In his first chapter, "Intelligence: The Development of a Concept", Eysenck concludes that culture-bound intelligence tests are admissible for pupil and student selection at school and university because "we are often justified in assuming considerable uniformity in cultural background among candidates"' (page 23). Eysenck gives no justification for his cultural-uniformity hypothesis.

His review of the evidence for a correlation between IQ and amplitude and latency of evoked cortical potentials is misleading. The figures that he displays in support of a strong correlation are taken from Ertl's early work which even Eysenck admits "suffered from technical and methodological deficiencies" (page 50). He then asserts that Shucard and Horn have also obtained "quite sizable correlations between AEP's [averaged evoked potentials] and IQ" (page 50). In fact, those investigators reported a correlation of only +0.24 for fluid intelligence and an absence of correlation for crystallized intelligence in the article cited by Eysenck. He also presents data from "our own laboratories" collected in about 1973. No details are given and no reference is made to any relevant publications in scholarly journals.

Eysenck's introductory text is also interspersed with political comments. For instance, in his discussion of IQ and job success, he tells us that "in our type of society there is little evidence of political
The Structure and Measurement of Intelligence. By Hans J. Eysenck. Pp.253. (Springer: Berlin, Heidelberg and New York, 1979.) DM 44, \$24.20.

and ideological interference with employment and promotion (except perhaps through union activity)" (page 88 ). In his final chapter "Intelligence and Society", Eysenck reports only one example of abuse of IQ tests for job selection: "it has been shown that on occasion white trade unionists in the U.S.A. have insisted on the use of irrelevant IQ tests for job selection in order to keep out black applicants'' (page 221).

"Does IQ Measure Intelligence?"' is the title of Eysenck's chapter on the validity of the IQ test. "We shall consider some outstanding studies" (page 79) in this chapter, he writes. One of those "outstanding studies" presented was the investigation performed during World War I by American Army psychologists with the Army Alpha, a group test of intelligence. Eysenck gives some of their evidence for the validity of the intelligence test, for example, their finding that illiterate enlisted men performed more poorly on the Army Alpha than literate enlisted men. Eysenck, however, neglects to present any of the items from that IQ test. Here are a few: (a) "Harvard University is in __ "; (b) "Yale University is at __. Here are a few more: (a) "Why is tennis good exercise?"; (b) "Lob is a term used in ___"; and (c) "a battle in racket very tennis useful is", which is to be rearranged into a sentence and then answered "true" or "false." The Army Alpha was the first IQ test used to classify national and racial groups according to native intelligence. "The great and universally agreed success of these tests caused many other countries to adopt them in later years and presents another external validation criterion for IQ tests as measures of intelligence"' (page 83) Eysenck writes.

The book also contains three chapters jointly authored by Fulker and Eysenck: a chapter on heredity, one on environment and a final chapter on socio-economic status. Their evaluation of the evidence supporting an environmentalist position is quite good overall. Their criticisms of the Heber study are reasonable and their presentation of Zajonc's confluence model is clear and fair. On the other hand, Fulker and Eysenck's arguments for the genetic position are in no way convincing and often misleading.

In his introductory chapter, Eysenck states (page 1): "I have tried to rewrite the relevant chapters in the history of the intelligence testing movement without including Burt's now doubtful data". Whereas Eysenck may have excluded Burt's questionable data from his historical accounts, Fulker and Eysenck present and make rather extensive use of Burt's fabricated numbers in their biometrical analyses. For example, in their analyses of IQ correlations for monozygotic twins reared apart, they include Burt's group-test correlation of 0.77 , asserting that "the main criticism [of Burt's data] concerns the individual test scores"' (page 109). That statement is false. Indeed, the main criticism concerns his group-test correlation: it remained constant at 0.771 from 1955 to 1966 in spite of large increases in sample size. Fulker and Eysenck also include Burt's questionable IQ correlations in their analyses of data for siblings reared apart (Table 5.4) and for unrelated children reared in the same home (Table 5.5). In their biometrical analyses of educational achievement, they use Burt's correlations for monozygotic twins reared together, for dizygotic twins reared together and for monozygotic twins reared apart (Table 5.14). Their biometrical exercises lead them to conclude that genotype-environment interaction and genotype-environment co-variance are small enough to be ignored. That conclusion contradicts the results of the statistical exercises presented in their final chapter on socio-economic status. The conclusions are as varied as the models.

Near the end of the book, there is an unnumbered chapter bearing the title "Eysenck and the Splitting of the IQ". A careful study of the primary sources reveals that if the IQ was split, it was split by Furneaux. In fact, Furneaux's first publication on this matter was apparently in Nature in $1952(170,37-38)$.

Summing up, Eysenck's new book is inappropriate for beginners, but rather entertaining for experts.

Donald D. Dorfman is Professor of Psychology in the Department of Psychology at the University of Iowa, Iowa City, Iowa. 